\title{
FDA halts then allows sales of Ariad's leukemia medication
}

US Food and Drug Administration (FDA)'s decision in late October 2013 to suspend marketing of Ariad's chronic myeloid leukemia (CML) drug Iclusig (ponatinib) sent shockwaves through the industry. Most clinicians weren't expecting a full-scale suspension, and neither apparently was the financial community, which sent the Cambridge, Massachusetts, biotech's shares down over $80 \%$, forcing the company into a radical downsizing. But on December 20, the regulators gave Ariad the go-ahead to resume marketing, albeit to a narrower patient population, and with Iclusig's relaunch, Ariad's shares leapt up. What's already clear, though, is that as FDA continues to encourage early access to drugs covering diseases with few or no available treatments through its accelerated approval pathway, there will be more Iclusigs. And Ariad isn't the first-nor will it be the last-biotech forced to rapidly change gear in order to survive.

The FDA on October 30 requested Ariad to withdraw its drug due to an "increased frequency of blood clots and narrowing of blood vessels" since the drug's approval in December 2012. The agency declared that almost a quarter $(24 \%)$ of patients in the phase 2 trial and almost half (48\%) in the phase 1 trial had experienced "serious adverse vascular events," including fatal and life-threatening heart attack, stroke and damaging loss of blood flow to the extremities, heart and brain. FDA also said it couldn't identify a safe dose level or exposure duration at that stage.

This was a damning indictment of a drug that had been accelerated through approval three months ahead of schedule and hailed as a major breakthrough in CML thanks in large part to its potent resistance profile. Iclusig is a multitargeted, small-molecule inhibitor. It is the most potent broadest range of mutations in the BCR-ABL kinase domain (the protein produced by the Philadelphia chromosome, a chromosomal abnormality associated with CML).

The news didn't come entirely out of the blue. Ariad's company release on October 9 said it was pausing patient enrollment in all Iclusig studies, and, nine days later, the biotech announced that owing to cardiovascular events in patients taking Iclusig, it was discontinuing a phase 3 trial pitting Iclusig

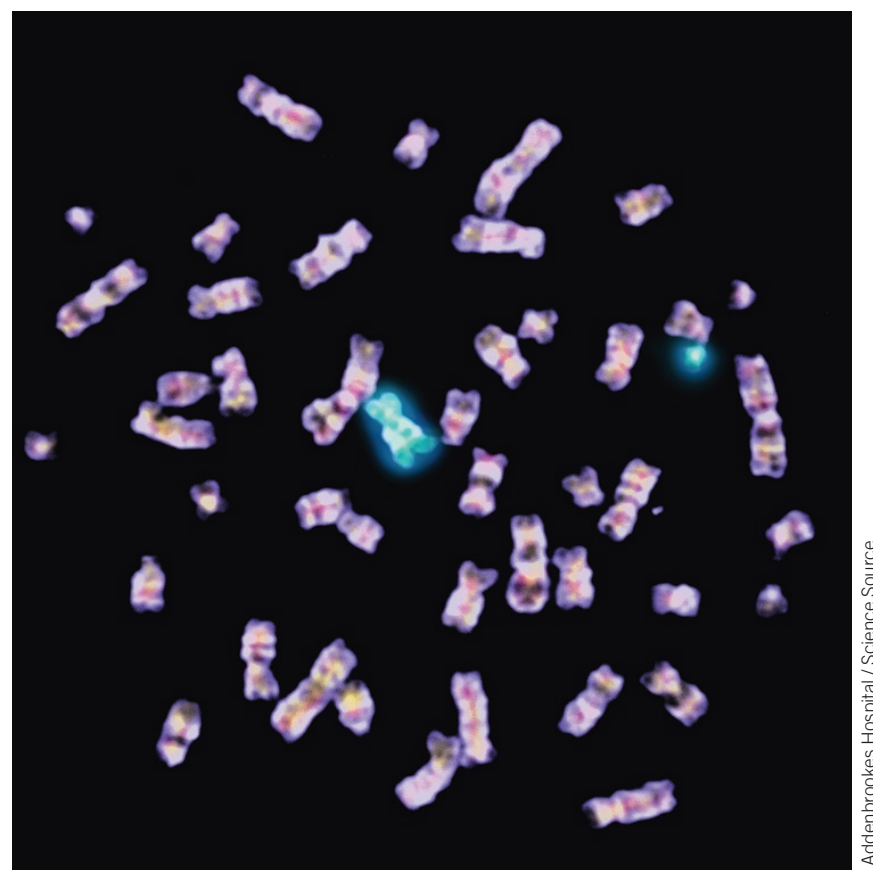

Philadelphia chromosome. In a bone marrow cell, defects on the second chromosome 22 cause chronic myelogenous leukemia.

against Novartis' well-established Gleevec (imatinib). And Iclusig has always carried a boxed warning about arterial thrombotic events.

But many treatments for a life-threatening condition carry boxed warnings, especially those approved under FDA's accelerated pathway. Cancer prescribers, and patients, are used to weighing up the possibility of side effects against a drug's benefit. And it wasn't as if Iclusig was a first-in-class treatment: there are four other tyrosine kinase inhibitors (TKIs) on the market for CML (Table 1). Each TKI has an individual side-effect profile, but none has-yet-thrown up any alarming safety signals.

FDA had initially determined that Iclusig's benefits outweighed its risks. Iclusig is the

\section{IN brief}

\section{Pfizer and Lilly shoulder novel pain-drug risks}

In October, New York-based Pfizer struck a deal with Eli Lilly of Indianapolis, to jointly develop its anti-nerve growth factor drug, tanezumab. Pfizer's painkiller, a humanized monoclonal antibody, was poised to be the first in an important new class of drugs for general pain. But in 2010, the US Food and Drug Administration (FDA) halted clinical trials of the entire drug class, including fulranumab, made by Janssen of Raritan, New Jersey, and REGN475 from Regeneron Pharmaceuticals, Tarrytown, New York, after too many participants experienced joint destruction (Nat. Biotechnol. 29, 173-174, 2011). In 2012 an advisory panel voted unanimously to allow trials to continue. "The panel was very persuasive in arguing that we have very inadequate pain treatments and that these drugs merit further study," says Joan Bathon, director of the rheumatology division, Columbia University Medical Center in New York, and who presented to the advisory panel an independent review of trial participants who had joint replacement surgery. The panel recommended that patients be closely monitored for joint-related adverse events and that concomitant use of nonsteroidal anti-inflammatory drugs (NSAIDs) be contraindicated, as people on NSAIDs had greater joint damage. The FDA has a partial hold on tanezumab studies, pending submission of nonclinical data to the FDA, which Pfizer anticipates submitting in early 2014. Pfizer and Eli Lilly will jointly develop and commercialize tanezumab. Lilly will pay Pfizer an undisclosed amount upfront-provided the FDA gives the drug the green light. Analysts have downgraded their expectations for the novel drug. Tanezumab's market, once estimated to be about

$\$ 1.2$ billion will likely be worth much less. "In these patients in the study the bone was collapsing. Given the risk of joint damage, it's going to be hard to study these drugs in patients with conditions like chronic back pain or neuropathic pain," says Bathon.

Gunjan Sinha

\section{IN their words}

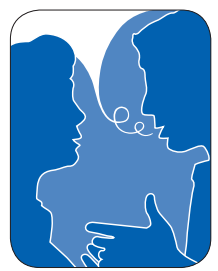

"When Josiah first told me about this idea, I thought it was bull ${ }^{* * * *}$, because I know how hard drug development is. But [looking to nature] is one main way antibiotics have been discovered in the past, and I really think that crowdsourcing has the potential to give us big advantages." Neurobiologist Mark Opal and biophysicist Josiah Zayner set up a citizen scientist site, The ILIAD Project, for testing natural products for antibiotic properties. (The Verge, 2 December 2013) 
IN brief

\section{Millionaire's gift to San Diego}

Businessman and philanthropist T. Denny Sanford committed \$100 million this November to create a stem cell center at the University of California in San Diego (UCSD). The Sanford Stem Cell Clinical Center will be directed by Lawrence Goldstein, who already directs UCSD's stem cell research and the existing Sanford Consortium for Regenerative Medicine. "The goal is very straightforward," Goldstein says, "and that is to accelerate the development of stem cell-based therapies for patients with intractable diseases." As San Diego already has many stem cell research institutions, Goldstein says the new center will seek to provide a "shared pipeline" to help those institutions identify therapeutic candidates for human trials. The center will also include a counseling component to advise patients on emerging therapies. One important investment will be in staff to guide researchers through the "regulatory gauntlet." Stem cell biologist Chad Cowan, a program director principal faculty at the Harvard Stem Cell Institute in Cambridge, Massachusetts, welcomes the regulatory support: "I think it's a smart move on Larry's part to consider investing some of the funds in the people who will actually educate the FDA [US Food and Drug Administration] to help pave the way for their translational trials." The gift, he says, "has the opportunity to put San Diego on the map, sort of the way the Broad Institute has for [Boston]."

\section{FDA tows personalized line}

The US Food and Drug Administration (FDA) on October 29 released a report describing the agency's ongoing efforts to improve its regulatory policies for personalized medicine. The report, titled Paving the Way for Personalized Medicine: FDA's Role in a New Era of Medical Product Development, falls short of outlining any new regulatory pathways but does offer a resource to help companies with such products in development to navigate the FDA. From 2009, when the agency created a personalized medicine staff within the device center's Office of In Vitro Diagnostics and Radiological Health, it has been intensifying its commitment to the field. In 2011, the agency's biologics center created a personalized medicine team. The recent report lists 22 guidance documents related to personalized medicine and numerous organizational changes at the agency to streamline regulatory oversight. But challenges remain. Coordinating regulatory oversight of therapeutics and their companion diagnostics requires expertise from multiple FDA centers. The process is complicated, and the agency stressed in the report that companies should communicate with the FDA early and frequently. "The biggest take-home message from this report is: When you are putting your program together for your company, you need to get in touch with the FDA and start a dialog," says Philip Arlen, CEO at Precision Biologics in Rockville, Maryland. "They are saying, 'Engage us'." only tyrosine kinase inhibitor active against the T315I mutation, for instance (about $20 \%$ of all BCR-ABL mutations are T315I). Iclusig's label was broader than for just those patients with the T315I mutation, though: it was indicated for all adults with chronic, accelerated or blast-phase CML, resistant or intolerant to prior TKI therapy, and for those with Philadelphia chromosomepositive, acute lymphoblastic leukemia that is resistant or intolerant to prior TKI therapy. "Pulling ponatinib is most problematic for T315I patients. Virtually all others have other [treatment] options," declares Peter Emanuel, director of the Winthrop P. Rockefeller Cancer Institute at the University of Arkansas for Medical Sciences in Little Rock. Ultimately, bone marrow transplant remains an option for some patients, too.

The fact that there are other treatments for CML likely influenced FDA's decision to pull Iclusig completely (the European Medicines Agency on November 22 only restricted the drug's use, though a further review announced December 6 may lead to additional changes). Indeed, Sprycel (dasatinib) and Tasigna (nilotinib) treat "most" of the mutations that develop as a result of Gleevec usage, according to Emanuel. But FDA may also have wanted to act firmly to avoid potential criticism of the accelerated pathway if further issues arose later on.

There are precedents for drug withdrawals, but not many. Even fewer return to market. The best-known come-back story is Cambridge, Massachusetts-based Biogen Idec's Tysabri (natalizumab) for multiple sclerosis. Tysabri was withdrawn in 2005 after reports connecting it to a rare viral disease that affects the brain and returned just over a year later with a boxed warning and risk management program. London-based AstraZeneca's lung cancer drug Iressa (gefitinib), restricted and ultimately withdrawn in the US, found a target subgroup among Asian patients with EGFR mutations.

So, was the agency too hasty in allowing Iclusig onto the market, and/or too generous with its label, given the limited data available at approval?

Yes, according to critics of the accelerated approval program, such as political scientist and Harvard University professor of government Daniel Carpenter. The current approval system is a "growing hodgepodge of exceptions to the rule of rigorous premarket review," Carpenter told Reuters in October 2013. He pointed to a study published just before Iclusig's withdrawal showing that drugs approved in 2008 under FDA's accelerated program had been tested, on average, in less than one-fifth the number of patients that drugs approved normally are, with many safety questions remaining unanswered as a result (http://archinte.jamanetwork.com/ article.aspx?articleID=1761917).

But some see Iclusig's withdrawal as proof that the system is working as it should. "What has occurred...is a clear demonstration that the accelerated approval pathway works," noted Mikkael Sekeres, chair of FDA's Oncology Drugs Advisory Committee, on November 26 in Oncology Times. Emanuelwho follows hundreds of CML patients-also thinks FDA was right to withdraw Iclusig, given the data. Yet despite the withdrawal, "I don't think FDA needs to be more cautious when it comes to cancer," he declares. "It's a balancing act. I don't think anyone could have foreseen that this TKI would have [such severe] cardiovascular side effects; nor should we jump to the conclusion and say all TKIs will have cardiovascular effects."

The other problem is that cardiovascular side effects come in various shapes and sizes, and the methods used in cancer drug trials to screen for, and categorize, these events remain unstandardized. Indeed, Ariad claims that FDA, since approving the drug, changed its definition of a "serious adverse event." At approval, it used "the standard US regulatory definition," according to the company's chief medical officer and senior vice president clinical R\&D Frank Haluska, talking on Ariad's third quarter results call on November 12. Yet the more recent FDA statistics used to back up the decision to withdraw were based on "a new definition of events... with more kinds of events clumped together, and more adverse events categorized as serious adverse events,' Haluska said. Had the same definitions been applied as at the time of approval, FDA's headline rates for serious adverse events would have been halved, from $48 \%$ to $22 \%$ in the phase 1 trial and from $24 \%$ to $12 \%$ in the phase 2 trial.

Despite the set-back, Ariad is still betting on Iclusig's potential to match the unmet clinical need. Fewer than half of CML patients resistant or intolerant to two or more TKIs have the mutation, according to 2011 data from UK-based research group Ipsos Healthcare. Ariad CEO Harvey Berger also points to FDA reports of over 200 US patients in the last month accessing Iclusig through single-patient Investigational New Drug applications, the only way to obtain Iclusig when it was withdrawn.

Dosing may also be tweaked to improve the risk-benefit profile. Data presented by Ariad at the American Society of Hematology (ASH) meeting in early 
December 2013 in New Orleans suggested that lower doses would reduce the risk of vaso-occlusive events, yet maintain efficacy in most patients. It also highlighted age and prior disease as influencing the rate of cardiovascular events-factors that may find themselves on revised clinical guidelines for the drug's use.

Ariad's drive to return Iclusig to as wide a portion of suitable US patients as possible is understandable: as the company's only marketed drug, it was propping up almost the entire valuation. The company slashed $40 \%$ of its workforce and pledged to reduce spending in 2014 by $35 \%$. With cash supplies extended until mid-2015, Berger is confident the firm won't need to go back to investors before Iclusig returns. But to protect itself from an unwanted takeover, Ariad announced a shareholder rights planalso known as a poison pill-the day after the withdrawal.

Citi Research analyst Jonathan Eckard in New York agreed back then that there would be a path back to market for Iclusig, even when sales might be limited. Eckard believes Ariad remains a "viable company that could turn profitable," thanks also to phase $1 / 2$ non-small cell lung cancer candidate AP26113. Indeed, "our basic strategy is unchanged. We're moving forward with filing [Iclusig] in Japan; [the plan in] Europe is in place, and we will solve these problems in the US," declares Berger, reflecting back on a similar FDA setback experience while head of R\&D at Philadelphia-based Centocor (now part of Johnson \& Johnson) over 20 years ago.

Berger underlines two lessons from the recent experience. First, be aware that a safetyfocused FDA could take a new line on how it accounts for adverse events. Second, consider studying multiple doses in pivotal trials, rather than focusing early on one optimal dose.

Iclusig's withdrawal and re-instatement won't likely affect FDA's accelerated approval pathway or its breakthrough therapy designation, says Citi's Eckard. There will be more Iclusig-like stories, where a first-round approval has to be adjusted. Each time this occurs, "both the Agency and the company will learn from it, and how to optimally approach it," notes Eckard.

Melanie Senior London

\section{Around the world in a month}

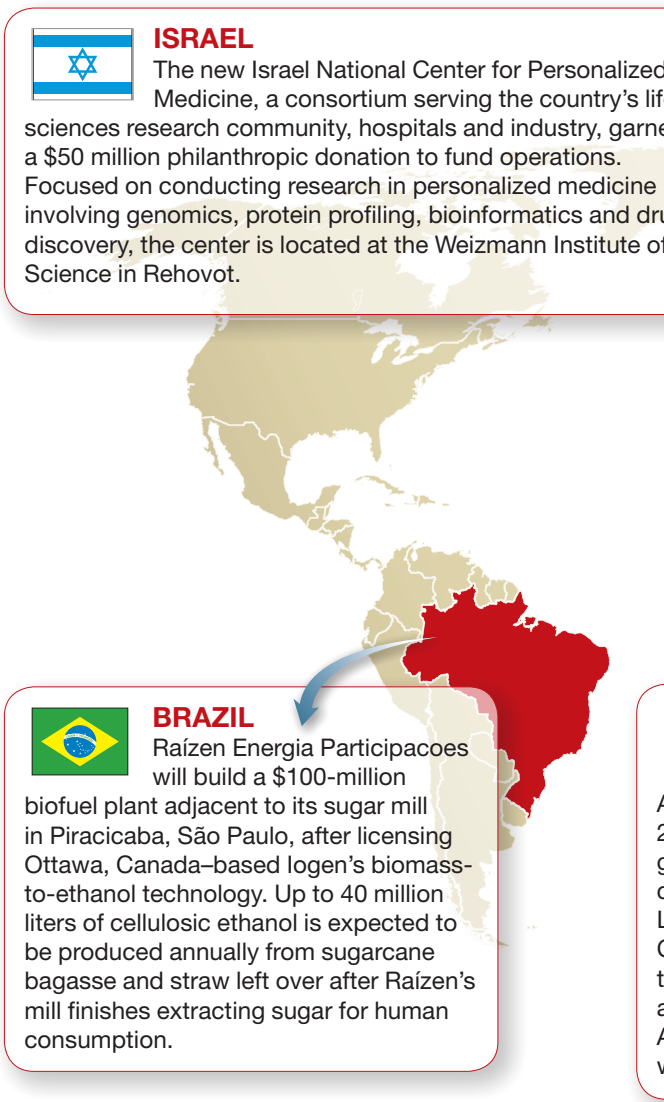

\section{( \\ (a)} (1)

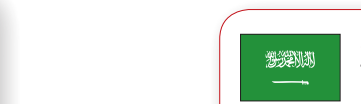

\section{SAUDI ARABIA}

The Saudi Human Genome Program launches 10 genome centers around the country to sequence try, garners Fo $\$ 50$ million philanthropic donation to fund operations. involving genomics, protein profiling, bioinformatics and drug discovery, the center is located at the Weizmann Institute of

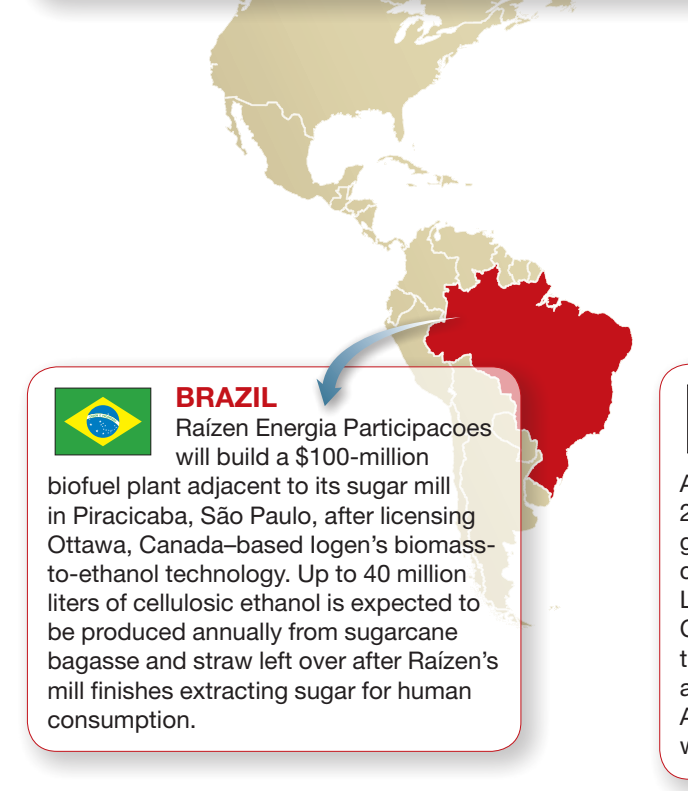

